\title{
Prognostic value and characterization of the ovarian cancer-specific antigen CA166-9
}

\author{
FANGXING JI ${ }^{1}$, XIAOHONG CHANG ${ }^{2}$, CAIYUN LIU ${ }^{2}$, LIN MENG $^{1}$, LIKE QU $^{1}$, JIAN WU ${ }^{1}$, \\ CHANZHEN LIU $^{2}$, HENG CUI $^{2}$ and CHENGCHAO SHOU ${ }^{1}$ \\ ${ }^{1}$ Key Laboratory of Carcinogenesis and Translational Research (Ministry of Education), Department of Biochemistry \\ and Molecular Biology, Peking University Cancer Hospital and Institute, Beijing 100142; \\ ${ }^{2}$ Gynecological Oncology Center, Peking University People's Hospital, Beijing 100044, P.R. China
}

Received January 21, 2015; Accepted March 9, 2015

DOI: $10.3892 /$ ijo.2015.3115

\begin{abstract}
COC166-9 is an ovarian cancer-specific monoclonal antibody, and COC166-9-based immunotherapy has been shown to possess killing effects against ovarian cancer cells in vitro and in vivo. However the antigen recognized by COC166-9 (COC166-9-Ag, CA166-9) has not been identified and the clinical significance of CA166-9 expression remains unknown. We found that CA166-9 was positive in $53.1 \%$ of ovarian cancer tissues. Expression of CA166-9 was strongly correlated with the cancer recurrence $(\mathrm{P}<0.001)$. Patients with positive CA166-9 had substantially shorter overall survival $(\mathrm{P}=0.026)$ and disease-free survival $(\mathrm{P}=0.002)$. $\mathrm{CA} 166-9$ was also shown to be an independent predictive factor for overall survival $(\mathrm{HR}=2.454, \mathrm{P}=0.016)$ and disease-free survival $(\mathrm{HR}=2.331, \mathrm{P}=0.021)$. We identified CA166-9 as human immunoglobulin $\gamma-1$ heavy chain constant region (IGHG1). Purified IGHG1 promoted proliferation, migration, and invasion of CA166-9-negative ovarian cancer HOC1A cells, whereas it had minimal effects on the phenotypes of CA166-9-positive ovarian cancer CAOV-3 cells. In addition, overexpression of IGHG1 enhanced migration of ovarian cancer cells. On the contrary, COC166-9 inhibited proliferation, migration, and invasion of CAOV-3 cells, but had no effects on HOC1A cells. Therefore, IGHG1 similarly to CA166-9, could play an important role in ovarian cancer development and may serve as a potential prognostic marker and a therapeutical target for ovarian cancer.
\end{abstract}

Correspondence to: Professor Chengchao Shou, Department of Biochemistry and Molecular Biology, Peking University Cancer Hospital and Institute, 52 Fucheng Road, Beijing 100142, P.R. China E-mail: cshou@vip.sina.com

Professor Heng Cui, Gynecological Oncology Center, Peking University People's Hospital, 11 Xizhimen South Street, Beijing 100044, P.R. China

E-mail: cuiheng20@163.com

Key words: ovarian cancer, CA166-9 antigen, prognosis, antigen cloning, IGHG1

\section{Introduction}

Ovarian cancer is a significant cause of morbidity and mortality in women, and the leading cause of death of gynecologic malignancies (1). Despite the use of operation-pathology stage, cytoreductive surgery, and new adjuvant chemotherapy, it is still associated with high mortality largely due to limited early detection methods. Serial combined testing for tumor markers including carcinoembryonic antigen (CEA), CA125 and CA153 are utilized. However, the lack of specificity and sensitivity of these cancer markers have hampered their general application in cancer detection and diagnosis (2-5). Therefore, it would be beneficial if an ovarian-specific specific biomarker was found.

In the late 1980s, Qian et al prepared a series of monoclonal antibodies specifically reacting with ovarian cancer tissues (6). COC166-9 is one of these antibodies and has relatively high specificity against ovarian cancer. Its reaction rate with ovarian cancer tissues was $75.6 \%$ in immunohistochemistry (7). Targeted therapy using COC166-9 conjugated to adriamycin-entrapped liposome resulted in longer survival for nude mice bearing ovarian cancer cell xenografts and ascites (8). Additionally, F(ab')2 fragment of COC166-9 was obtained by ficin digestion, which had better immunoactivity and radioimmunoimaging than the intact monoclonal antibody (9). The anti-idiotypic antibody 6B11 against COC166-9 was also generated and humanized (10). The sera tested by $6 \mathrm{~B} 11$ presented $67.3 \%$ positivity of ovarian epithelial carcinoma, much higher than that of the benign ovarian tumor or uterine tumors (11). Besides, the recombinant single-chain variable fragment $(\mathrm{ScFv})$ of $6 \mathrm{~B} 11$ has demonstrated killing effects against ovarian cancer cells in vitro and in vivo (12-14). Moreover, a study on identification of antigen-specific T cell eptitopes in 6B11 found that the light chain CDR3 peptide and heavy chain CDR3 peptide are the MHC class I and class II epitopes of 6B11, respectively. The combination of MHC class I and class II epitopes is more effective than 6B11 in inducing specific cellular immune response against ovarian cancer (15). However, the clinical significance of the antigen recognized by COC166-9 (COC166-9-Ag, here we name this antigen as CA166-9) was not evaluated and the CA166-9 remained to be characterized. 
In this study, we analyzed the expression profile of CA166-9 in tumor tissues from 111 ovarian cancer patients with $>5$-year follow-up. The prognostic value of CA166-9 for ovarian cancer was also assessed. We further identified CA166-9 as human immunoglobulin $\gamma-1$ heavy chain (IGHG1) constant region. By in vitro assays, CA166-9 was shown to promote proliferation, migration, and invasion of a subset of ovarian cancer cells.

\section{Materials and methods}

Patients and clinical samples. The collection of tissue samples was approved and supervised by the Research Ethics Committee of Peking University People's Hospital. Written informed consents were obtained from all the patients prior to operation. A total of 111 patients who underwent surgical resection of primary ovarian cancer between January 2001 and December 2005 in Peking University People's Hospital were investigated. Formalin-fixed and paraffin-embedded specimens from these patients were collected. No patients received any type of pre-surgical therapy. Histological classification and clinic pathological staging were performed according to the TNM classification of UICC.

Ovarian cancer cell lines and cell culture. The ovarian carcinoma cell line CaOV3 and SKOV3 (ATCC, Manassas, VA, USA) were cultured in DMEM and RPMI-1640 medium plus $10 \%$ fetal calf serum (FCS), respectively. The ovarian carcinoma cell line HOC1A and 3AO, derived from poorly differentiated ovarian cancer surgical specimens, were cultured in RPMI-1640 medium with $10 \%$ FCS. These cells were routinely cultured at $37^{\circ} \mathrm{C}$ in a humidified atmosphere of $5 \% \mathrm{CO}_{2}$. All culture media and FCS were from Invitrogen (Carlsbad, CA, USA).

Immunohistochemistry and immunocytochemistry. Archived, formalin-fixed, paraffin-embedded tissue sections were obtained from Gynecologic Oncology Center, Peking University People's Hospital. Four- $\mu$ m thick tissue slides were deparaffinized with xylene and rehydrated through a graded alcohol series. Endogenous peroxidase activity was then blocked by incubation in $3 \%$ hydrogen peroxide-methanol for $10 \mathrm{~min}$. After washing with phosphate-buffered saline, the slides were blocked with $5 \%$ skim milk for $60 \mathrm{~min}$ and then incubated with monoclonal antibody COC166-9 $(2 \mu \mathrm{g} / \mathrm{ml})$ overnight at $4^{\circ} \mathrm{C}$. Antibody binding was visualized by a standard streptavidin immunoperoxidase reaction, followed by chromogen detection with diaminobenzidine for $10 \mathrm{~min}$ and haematoxylin counterstaining. The results were judged by two pathologists independently and any specimen with $>10 \%$ positive staining cells was classified as positive. Normal mouse IgG was used as negative control. For immunocytochemistry, the human ovarian cancer CAOV3, SKOV3, HOC1A and $3 \mathrm{AO}$ cells were plated onto glass coverslips. After $24 \mathrm{~h}$, the cells were fixed in $4 \%$ paraformaldehyde for $10 \mathrm{~min}$, and the cells were stained for immunocytochemistry by following the procedures used for immunohistochemistry.

Preparation of immunoaffinity column using COC166-9 antibody. Purified COC166-9 (6 mg) was dialyzed against the coupling buffer $\left(0.1 \mathrm{M} \mathrm{NaHCO}_{3} \mathrm{pH} 8.3,0.5 \mathrm{M} \mathrm{NaCl}\right)$ for two times. $0.7 \mathrm{~g}$ cyanogen bromide (CNBr) activated Sepharose 4B (Amersham Pharmacia Biotech Inc., Piscataway, $\mathrm{NJ}$, USA) was added to the $1 \mathrm{mM} \mathrm{HCl}$ and incubated at room temperature for $15 \mathrm{~min}$. After the reaction, the supernatant was disposed quickly with a funnel with a vacuum filtration. COC166-9, dissolved in the coupling buffer $(5 \mathrm{ml})$, was added to the slurry immediately when the supernatant was removed, and incubated for $2 \mathrm{~h}$ at room temperature with gentle rotating. After centrifugation at $1,000 \mathrm{rpm}$ for $2 \mathrm{~min}$ at $4^{\circ} \mathrm{C}$, the immunoaffinity resin was washed again with coupling buffer. Ethanolamine $(10 \mathrm{ml})(1 \mathrm{M} \mathrm{pH} 8.0)$ was added to the resin and incubated for $2 \mathrm{~h}$ at room temperature. The immunoaffinity resin was packed into a 5-ml plastic mini-column. The column was washed three times alternately with acetate washing buffer $(0.1 \mathrm{M}$ sodium acetate $\mathrm{pH} 4.0,0.5 \mathrm{M} \mathrm{NaCl})$ and Tris washing buffer (0.1 M Tris- $\mathrm{HCl} \mathrm{pH} 8.0,0.5 \mathrm{M} \mathrm{NaCl})$. The wash-out was recovered to measure unbound protein by detecting their absorbance at $280 \mathrm{~nm}$ for determination of coupling efficiency. The immunoaffinity resin was washed with PBS until the absorbance at $280 \mathrm{~nm}$ was $<0.02$. The column was stored at $4^{\circ} \mathrm{C}$ in PBS containing $0.02 \%$ sodium azide.

Purification of CA166-9 from the ascites of ovarian cancer patient by immunoaffinity column chromatography. The ascites of ovarian cancer patient was obtained from Gynecologic Oncology Center, Peking University People's Hospital. The ascites was diluted with PBS and then filtered using a MILLEX-HV filter $(0.45 \mu \mathrm{m}$, Millipore, MA, USA) to remove insoluble portions. The filtrate was loaded on the immunoaffinity column and allowed to stand overnight at $4^{\circ} \mathrm{C}$. It was washed with PBS until the unbinding proteins disappeared by analyzing the absorbance at $280 \mathrm{~nm}$. The column was then eluted with glycine buffer $(0.1 \mathrm{M}, \mathrm{pH} 2.7)$, and protein concentration in individual fractions ( $1 \mathrm{ml}$ each) was determined by absorbance at $280 \mathrm{~nm}$.

Western blotting. Equal amount of purified antigens were loaded in $12 \%$ SDS-PAGE and electroblotted to a nitrocellulose membrane. Non-specific binding was blocked with $5 \%$ non-fat milk in PBS for $1 \mathrm{~h}$ at room temperature. Then, the membrane was incubated with COC166-9 $(2 \mu \mathrm{g} / \mathrm{ml})$ overnight at $4^{\circ} \mathrm{C}$, rinsed with PBST five times, followed by incubation with HRP-labeled goat anti-mouse IgG for $45 \mathrm{~min}$. After five washes with PBST, the bands were developed with the enhanced chemiluminescence (ECL) system (Amersham, Uppsala, Sweden).

ELISA. The microplates were coated with 1:5,000 dilution of ascites from ovarian cancer patients or $5 \mu \mathrm{g} / \mathrm{ml}$ human $\mathrm{IgG}$ in $0.1 \mathrm{M}$ of bicarbonate buffer $(\mathrm{pH} 9.5)$ then blocked with $5 \%$ skim milk in PBS. COC166-9 $(2 \mu \mathrm{g} / \mathrm{ml})$ was added to each well. In ELISA inhibition assay, 0.2, 0.5, 1, 2, and $5 \mu \mathrm{g} / \mathrm{ml}$ human $\mathrm{IgG}$ or purified antigen protein were incubated with $2 \mu \mathrm{g} / \mathrm{ml} \mathrm{COC} 166-9$ for $2 \mathrm{~h}$ at $4^{\circ} \mathrm{C}$ before adding to the wells. Bound antibodies were detected using HRP-conjugated antimouse IgG antibody (Zhong Shan Co., Beijing, China) with a peroxidase substrate.

Peptide mass fingerprint by MALDI-TOF MS. Protein bands were excised from coomassie blue stained gel and trans- 
ferred to microcentrifuge tubes. In gel trypsin digestion was conducted. For MALDI-TOF MS analysis, $1 \mathrm{ml}$ of the peptide was mixed with $1 \mathrm{ml}$ matrix solution [CHCA, saturated solution in ACN: 0.1\% TFA (1:1)] on the target plate, and analyzed with a MALDI-TOF mass spectrometer (Autoflex; Bruker, Karlsruhe, Germany) in reflector mode over a mass range of 1,000-3,000 Da. For each sample, spectra at several different positions were combined to generate a peptide mass fingerprint (PMF) for database searches for protein identification. The peptide mass fingerprints obtained were searched against the MASCOT database.

Immunoprecipitation. To confirm that the antigen protein was human $\operatorname{IgG}$, immunoprecipitation with streptococcal protein G-conjugated beads was performed. Ovarian cancer ascites were diluted 1,000-fold in PBS, and incubated with $40 \mu 125 \%$ protein $\mathrm{G}$ agarose slurry for $2 \mathrm{~h}$ at $4^{\circ} \mathrm{C}$. The protein G-conjugated beads were recovered by centrifugation at 5,000 rpm at room temperature. The supernatant was transferred to another tube. Proteins that bind to the beads were then eluted with glycine buffer $(0.1 \mathrm{M} \mathrm{pH} 2.7)$. Both the supernatant and binding proteins were subjected to ELISA for further evaluation.

Cloning and expression of IGHG1 constant region. The total RNA was extracted from $5 \times 10^{6}$ CAOV3 cells with TRIzol reagent (Invitrogen). A CAOV3 cDNA library was prepared by RT-PCR with Reverse Transcription kit (Promega, Madison, WI, USA) according to the manufacturer's instructions. The full length IGHG1 constant region cDNA was then obtained with the CAOV3 cDNA library as template. Sense primer: 5'-CGC GGA TCC ATG GGA CCG TCA GTC TTC CTC TT-3'; anti-sense primer: 5'-CCG CTC GAG TCA TTT ACC CGG AGA CAG GGA G-3. The cDNA was inserted into the pcDNA3 vector (Invitrogen) and pcDNA3-IGHG1 constant region (pcDNA3-IGHG1cr) was transfected into CA166-9 negative ovarian cancer $3 \mathrm{AO}$ cells by Lipofectimine 2000 (Invitrogen) according to the manufacturer's instructions.

Generation of mouse polyclonal antibody against CA166-9. Six- to 8-week-old BALB/c mice (Animal Center of the Chinese Medical Academy, Beijing, China) were firstly immunized subcutaneously with $50 \mu \mathrm{g}$ purified antigen for each that was emulsified in complete Freund's adjuvant (Sigma, St. Louis, MO, USA). Mice were boosted four times with the antigen emulsified in incomplete Freund's adjuvant every 3 weeks. Sera were taken on day 0 (preimmune) and 7 days after the third and fifth immunization.

Cell proliferation assay. The MTT (3-(4,5-dimethylthiazol2-yl)-2,5-diphenyltetrazolium bromide) assay was used to assess proliferation of ovarian cancer cells. Ovarian cancer cells were seeded in a 96-well culture plate at a density of 2,000 cells per well in a volume of $100 \mu \mathrm{l}$. The cells were allowed to adhere for $3 \mathrm{~h}$ at $37^{\circ} \mathrm{C}$ at $5 \% \mathrm{CO}_{2}$, and $50 \mu \mathrm{l}$ culture medium with or without purified IGHG1 or COC166-9 were subsequently added. The concentrations of IGHG1 and COC166-9 were 20 and $10 \mu \mathrm{g} / \mu \mathrm{l}$, respectively. The cells were cultured for 24, 48, 72 and $96 \mathrm{~h}$. During the last $4 \mathrm{~h}$ of the assay, the culture was pulsed with $0.5 \mathrm{mM}$ MTT per well resulting in an insoluble purple formazan product. The medium was aspirated and the precipitates dissolved in $150 \mu \mathrm{l}$ of dimethylsulfoxide (DMSO) buffered at $\mathrm{pH}$ 10.5. The absorbance was read at $492 \mathrm{~nm}$ using an enzyme-linked immunosorbent assay (ELISA) plate reader. The results presented are the mean of 3 separate experiments.

Cell migration and invasion assay. Cell migration assay was performed by using culture medium-treated $6.5-\mathrm{mm}$ Transwell chamber with $8.0-\mu \mathrm{m}$ polycarbonate membranes. The bottom chamber was filled with $800 \mu \mathrm{l}$ medium containing $10 \%$ FCS. Cells were harvested from tissue culture plates by serum-free medium, and then were seeded onto the top chamber of each Transwell at a density of $2 \times 10^{5}-1 \times 10^{6}$ cells $/ \mathrm{ml}$ per well $(100 \mu \mathrm{l} /$ chamber) in serum-free medium, and subsequently, the antibody COC166-9 was added with a final concentration of $10 \mu \mathrm{g} /$ $\mu 1$. Alternatively, purified IGHG1 was used at $10 \mu \mathrm{g} / \mu \mathrm{l}$. After incubation in a humidified incubator with $5 \% \mathrm{CO}_{2}$ at $37^{\circ} \mathrm{C}$ for 24-48 h, non-migratory cells were scraped off from the top of the Transwell with a cotton swab. The cells attached to the bottom side of the membrane were fixed by methanol, stained with $5 \%$ crystal violet, and counted under a light microscope. The results presented are the mean of 3-4 separate experiments.

The invasion assay was similar to the migration assay described above, except that the upper side of the membranes was coated with a uniform thickness $(2 \mathrm{~mm}$ ) of $100 \mu \mathrm{g}$ Matrigel for $60 \mathrm{~min}$ at room temperature before the cells were added.

Statistical analysis. A standard $\chi^{2}$ test was performed to examine the association between CA166-9 expression and the clinicopathologic parameters. Survival curves were estimated by the Kaplan-Meier method and compared with the log-rank test. A multivariate analysis was performed by using the Cox regression model (a backward selection) to analysis whether a factor was an independent predictor of DFS. Hazard ratios (HRs) with $95 \%$ confidence intervals were estimated. A two-tailed P-value of $<0.05$ was considered statistically significant. All statistical analyses were performed with SPSS v13.0 software.

\section{Results}

Correlation between CA166-9 expression and clinicopathologic parameters. CA166-9 protein expression in tumor specimens of ovarian cancer was determined by immunohistochemical staining (IHC). CA166-9 protein localization was revealed as granulated loci in ovarian adenocarcinoma (Fig. 1A). The staining was mainly localized in the cytoplasm and loosely in the nucleus. There was no CA166-9 expression in benign adenoma (Fig. 1A). High levels of CA166-9 expression were found in 59 out of 111 neoplasms (53.1\%). Regarding the clinicopathologic parameters, we observed that positive CA166-9 expression was closely associated with relapse $\left(\chi^{2}=5.316, P=0.021\right.$, Table I). No significant correlation between CA166-9 status and other clinicopathologic characteristics (e.g., age, clinical stage, tumor size, or CA125) was found in this cohort (Table I).

Relationship of CA166-9 expression with the survival of ovarian cancer patients. As expected, stage and relapse 
A
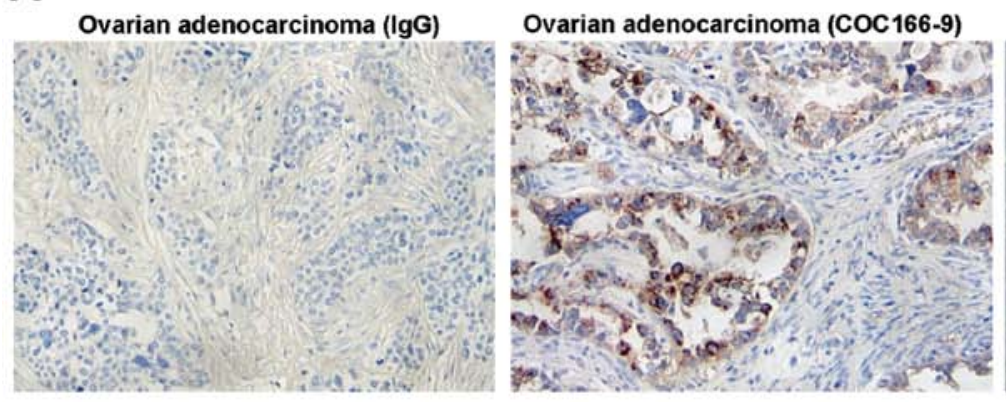

Benign ovarian adenoma (COC166-9)

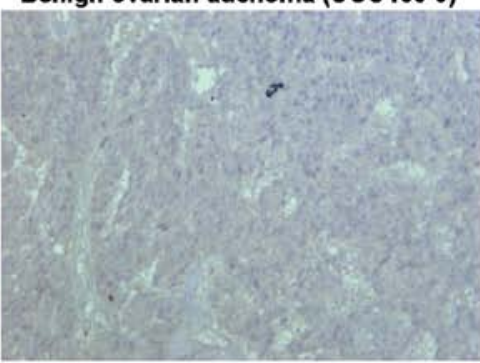

\section{B}

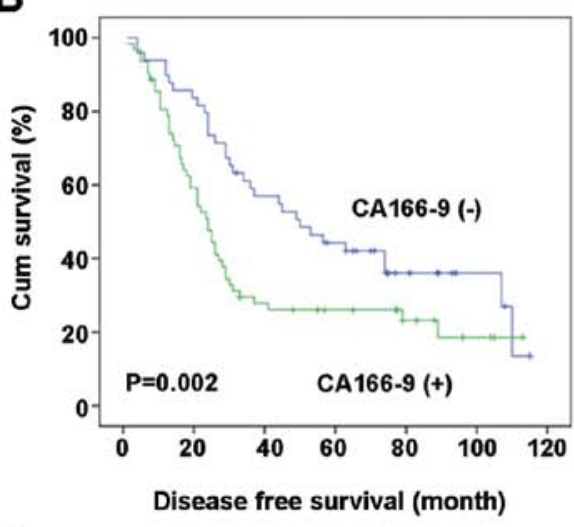

C

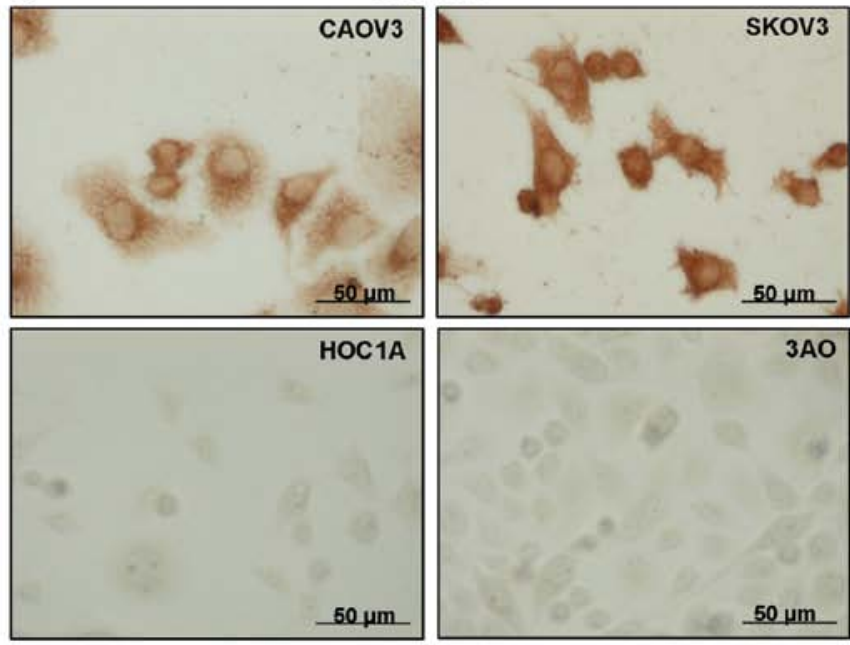

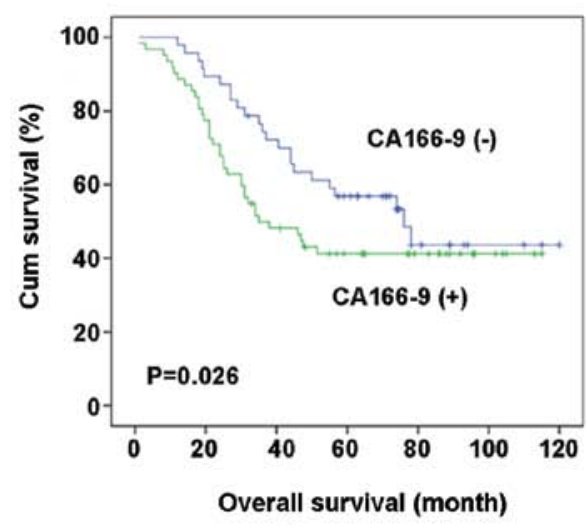

D

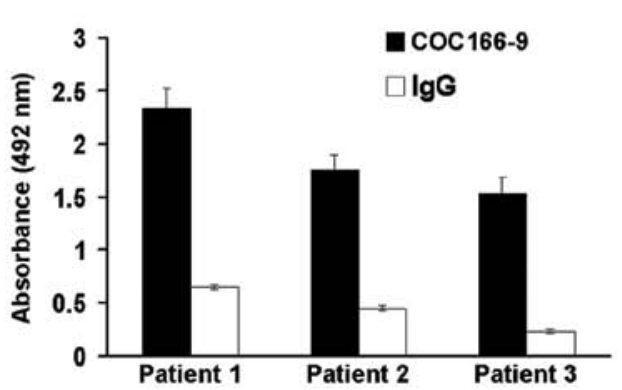

Figure 1. Expression profile and prognostic value of CA166-9 in ovarian cancer tissues, cancer cells, and ascites. (A) Immunohistochemical staining of ovarian cancer tissues with COC166-9 or IgG (negative control). Magnification, x200. (B) Kaplan-Meier estimates of overall survival (OS) and disease-free survival (DFS) with respect to CA166-9 status in ovarian cancer tissues. (C) Immunocytochemical staining of indicated ovarian cancer cells with COC166-9. (D) Detection of 3 cases of ovarian cancer ascites with COC166-9 by ELISA assay.

were significantly associated with clinical outcome $(\mathrm{P}<0.001$, Table II). Patients with a high level of CA166-9 expression also exhibited a trend towards shorter overall survival (OS) and disease-free survival (DFS) compared to patients with a low level of CA166-9 (OS, P=0.026; DFS, P=0.002, Fig. 1B and Table II). A multivariate analysis showed that CA166-9 expression was an independent prognostic marker for OS or DFS (OS: HR 2.454, P=0.016; DFS: HR 2.331, $\mathrm{P}=0.021$, Table III).

CA166-9 expression in ovarian cancer cell and ovarian cancer ascites. Immunocytochemistry analysis with COC166-9 demonstrated that CA166-9 was detectable in the cytoplasm and nuclei of ovarian cancer cells CAOV3 and SKOV3, whereas the HOC1A and 3AO did not show any CA166-9 expression (Fig. 1C), indicating the expression of CA166-9 is cell type-specific. CA166-9 was also found in the ascites from three ovarian cancer patients by ELISA assay (Fig. 1D).

Identification of CA166-9 as IGHGI constant region. To identify the CA166-9, ovarian cancer ascites were subjected to the immunoaffinity column chromatography. The purified antigens were resolved by SDS-PAGE (Fig. 2A, left) and probed with the COC166-9 by western blotting (Fig. 2A, 
Table I. Correlation of CA166-9 expression with clinicopathologic factors.

\section{CA166-9}

\begin{tabular}{|c|c|c|c|c|c|}
\hline Classification & $\begin{array}{c}\text { Cases } \\
\text { (n) }\end{array}$ & $\begin{array}{c}\text { Negative } \\
(\%)\end{array}$ & $\begin{array}{c}\text { Positive } \\
(\%)\end{array}$ & $\chi^{2}$ & P-value \\
\hline \multicolumn{6}{|l|}{ Age } \\
\hline$<50$ & 37 & $19(51.4)$ & $18(48.6)$ & 0.452 & 0.501 \\
\hline$\geq 50$ & 74 & 33 (44.6) & $41(55.4)$ & & \\
\hline \multicolumn{6}{|l|}{ Tumor size } \\
\hline$<6 \mathrm{~cm}$ & 73 & $38(52.1)$ & 35 (47.9) & 3.627 & 0.057 \\
\hline$\geq 6 \mathrm{~cm}$ & 34 & $11(32.4)$ & $23(67.6)$ & & \\
\hline \multicolumn{6}{|l|}{ FIGO stage } \\
\hline $\mathrm{I} / \mathrm{II}$ & 38 & $17(44.7)$ & $21(55.3)$ & 0.103 & 0.748 \\
\hline III/IV & 73 & 35 (47.9) & $38(52.1)$ & & \\
\hline \multicolumn{6}{|l|}{ CA125 } \\
\hline$\leq 35$ & 7 & $3(42.8)$ & $4(57.2)$ & 1.169 & 0.280 \\
\hline$>35$ & 104 & $46(44.2)$ & $58(55.8)$ & & \\
\hline \multicolumn{6}{|l|}{ Relapse } \\
\hline Negative & 33 & $21(63.6)$ & $12(36.4)$ & 5.316 & 0.021 \\
\hline Positive & 78 & 31 (39.7) & $47(60.3)$ & & \\
\hline
\end{tabular}

FIGO, the International Federation of Gynecology and Obstetrics.

right). Five protein bands at 170, 130, 7055 and $45 \mathrm{kDa}$ were successfully purified from the ovarian cancer ascites and were named as CA166-9 band A, B, C, D, and E, respectively. By mass spectrometry analysis, we obtained 13 peptide sequences from band A, 23 peptide sequences from band B, 16 peptide sequences from band $\mathrm{C}, 18$ peptide sequences from band $\mathrm{D}$, and 14 peptide sequences from band $\mathrm{E}$. The peptides were all matched to human immunoglobulin $\gamma-1$ heavy chain (IGHG1) constant region by basic local alignment search tool (MASCOT) homology search (Fig. 2B). ELISA assay revealed that both purified CA166-9 and human IgG could abolish COC166-9's reaction with ovarian cancer ascites in a dose-dependent manner, however purified mouse IgG had no inhibitory effect (Fig. 2C). Similarly, results of immunohistochemistry inhibition analysis demonstrated that staining of successive sections of ovarian cancer specimens by COC166-9 was interfered by purified human $\mathrm{IgG}$ and CA166-9, but not by mouse IgG (Fig. 2D). Since the streptococcal protein $\mathrm{G}$ binds to the Fc fragment of $\operatorname{IgG}(16)$, it is reasonable to assume that the putative CA166-9, IGHG1 constant region protein could also associate with protein $\mathrm{G}$. To confirm this predication, immunoprecipitation was performed with protein G-conjugated beads plus ascites solution from ovarian cancer patient. The ascites, protein eluted from protein G-conjugated beads after incubated with the ascites, and ascites after absorbed with the protein $\mathrm{G}$ were, respectively, coated onto the microtiter plates for ELISA assay with COC166-9. The results showed that COC166-9 had strong positive reactivity with the ascites or eluted protein, but a negative reactivity with the ascites after being absorbed with the protein $\mathrm{G}$ (Fig. 2E). These results indicated the antigen recognized by COC166-9 was IgG-like protein.

Mice immunized with purified antigen produced polyclonal antibody against CA166-9. Two of 3 mice immunized with purified antigen generated polyclonal antibody against CA166-9. The sera were subjected to ELISA assay in which

Table II. Univariate analysis of the prognostic factors in ovarian cancer patients.

\begin{tabular}{|c|c|c|c|c|c|c|}
\hline \multirow[b]{2}{*}{ Variables } & \multicolumn{3}{|c|}{ Overall survival (OS) } & \multicolumn{3}{|c|}{ Disease-free survival (DFS) } \\
\hline & HR & $95 \% \mathrm{CI}$ & P-value & HR & $95 \% \mathrm{CI}$ & P-value \\
\hline \multicolumn{7}{|l|}{ Age } \\
\hline$\geq 50$ vs $<50$ & 1.693 & $0.953-3.005$ & 0.073 & 1.239 & $0.775-1.983$ & 0.371 \\
\hline \multicolumn{7}{|l|}{ Tumor size } \\
\hline$\geq 6 \mathrm{vs}<6 \mathrm{~cm}$ & 1.748 & $1.184-2.579$ & 0.592 & 0.698 & $0.432-1.127$ & 0.141 \\
\hline \multicolumn{7}{|l|}{ Relapse } \\
\hline Positive vs negative & 5.150 & $1.107-21.264$ & $<0.001$ & 8.615 & $5.806-12.781$ & $<0.001$ \\
\hline \multicolumn{7}{|l|}{ CA125 } \\
\hline$>35$ vs $\leq 35$ & 4.875 & $0.675-35.210$ & 0.116 & 3.268 & $0.802-13.320$ & 0.098 \\
\hline \multicolumn{7}{|l|}{ FIGO stage } \\
\hline III/IV vs I/II & 3.994 & $1.960-18.141$ & $<0.001$ & 3.539 & $1.945-17.505$ & $<0.001$ \\
\hline \multicolumn{7}{|l|}{ COC166-9-Ag } \\
\hline Positive vs negative & 1.504 & $0.890-2.542$ & 0.026 & 1.778 & $1.129-2.799$ & 0.002 \\
\hline
\end{tabular}

HR, hazard ratio; CI, confidence interval. 
Table III. Multivariate analysis of the prognostic factors in ovarian cancer patients.

\begin{tabular}{|c|c|c|c|c|c|c|}
\hline \multirow[b]{2}{*}{ Variables } & \multicolumn{3}{|c|}{ Overall survival (OS) } & \multicolumn{3}{|c|}{ Disease-free survival (DFS) } \\
\hline & HR & $95 \%$ CI & P-value & HR & $95 \% \mathrm{CI}$ & P-value \\
\hline Age & & & & & & \\
\hline$\geq 50$ vs $<50$ & 0.964 & $0.658-1.410$ & 0.848 & 1.485 & $0.893-2.467$ & 0.127 \\
\hline $\begin{array}{l}\text { Tumor size } \\
\geq 6 \text { vs }<6 \mathrm{~cm}\end{array}$ & 1.284 & $0.706-2.336$ & 0.043 & 1.740 & $0.437-1.253$ & 0.023 \\
\hline Relapse & & & & & & \\
\hline Positive vs negative & 7.808 & $2.326-26.210$ & 0.001 & 7.137 & $10.105-84.151$ & $<0.001$ \\
\hline $\begin{array}{l}\text { CA125 } \\
>35 \text { vs } \leq 35\end{array}$ & 0.345 & $0.046-2.567$ & 0.299 & 0.872 & $0.199-3.824$ & 0.856 \\
\hline $\begin{array}{l}\text { FIGO stage } \\
\text { III/IV vs I/II }\end{array}$ & 2.026 & $0.874-4.695$ & 0.010 & 2.886 & $0.934-3.810$ & 0.007 \\
\hline $\begin{array}{l}\text { COC166-9-Ag } \\
\text { Positive vs negative }\end{array}$ & 2.454 & $0.825-2.563$ & 0.016 & 2.331 & $1.383-3.929$ & 0.021 \\
\hline
\end{tabular}

A

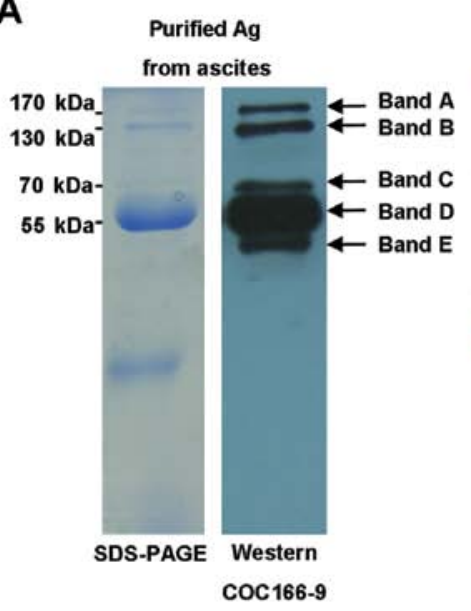

B

IGHG1 human

ASTKGPSVFP LAPSSKSTSG GTAALGCLVK DYFPEPVTVS WNSGALTSGV HTFPAVLQSS

GLYSLSSVVT VPSSSLGTQT YICNVNHKPS NTKVDKKVEP KSCDKTHTCP PCPAPELLGG

PSVFLFPPKP KDTLIISRTP EVTCVVVVS HEDPEVKFNW YVDGVEVHNA KTKPREEQYN

STYRVVSVLT VLHQDWLNGK EYKCKVSNKA LPAPIEKTIS KAKGQPREPQ VYTLPPSRDE

LTKNQVSLTC LVIGFYPSDI AVEWESNGQP ENNYKTTPPV LDSDGSFFLY SKLTVDKSRM

QQGNVFSCSV IHEALHNHYT QKSLSLSPGK
C
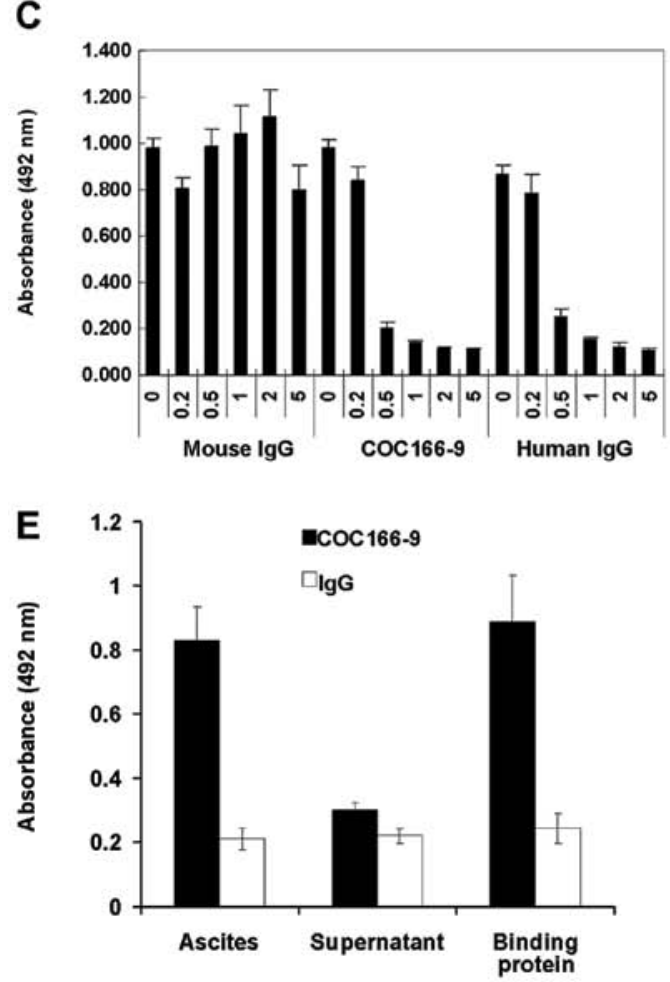

D

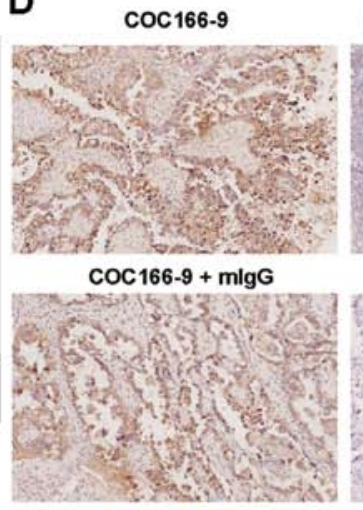

Coc166-9 + Human IgG

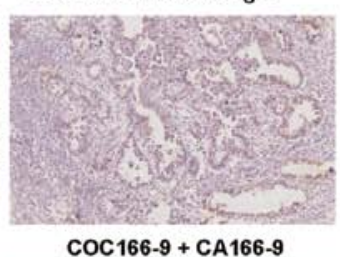

COC166-9 + CA166-9

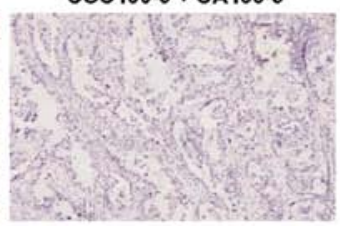

Figure 2. Purification and characterization of CA166-9. (A) SDS-PAGE analysis (left panel) and western blotting (right panel) of purified CA166-9 from ascites of patient with ovarian cancer. (B) Protein sequence of IGHG1 constant region. A total coverage of $39.7 \%$ was achieved. Matched peptide sequences are marked in red. (C) ELISA analysis of ascites of ovarian cancer patient, with indicated amount $(\mu \mathrm{g})$ of mouse $\mathrm{IgG}$, purified CA166-9, and purified human IgG for competition. (D) Immunohistochemical staining of ovarian cancer tissues by COC166-9, with human $\mathrm{IgG}$, mouse $\mathrm{IgG}$, and purified CA166-9 as competitor. (E) ELISA analysis of purified CA166-9, protein eluted from Protein-G and the ascites after absorbed with Protein-G. 
A

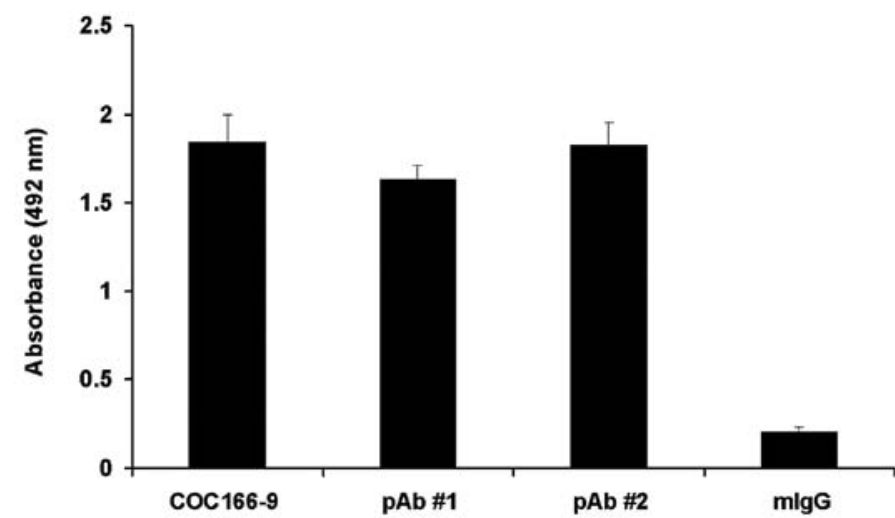

B
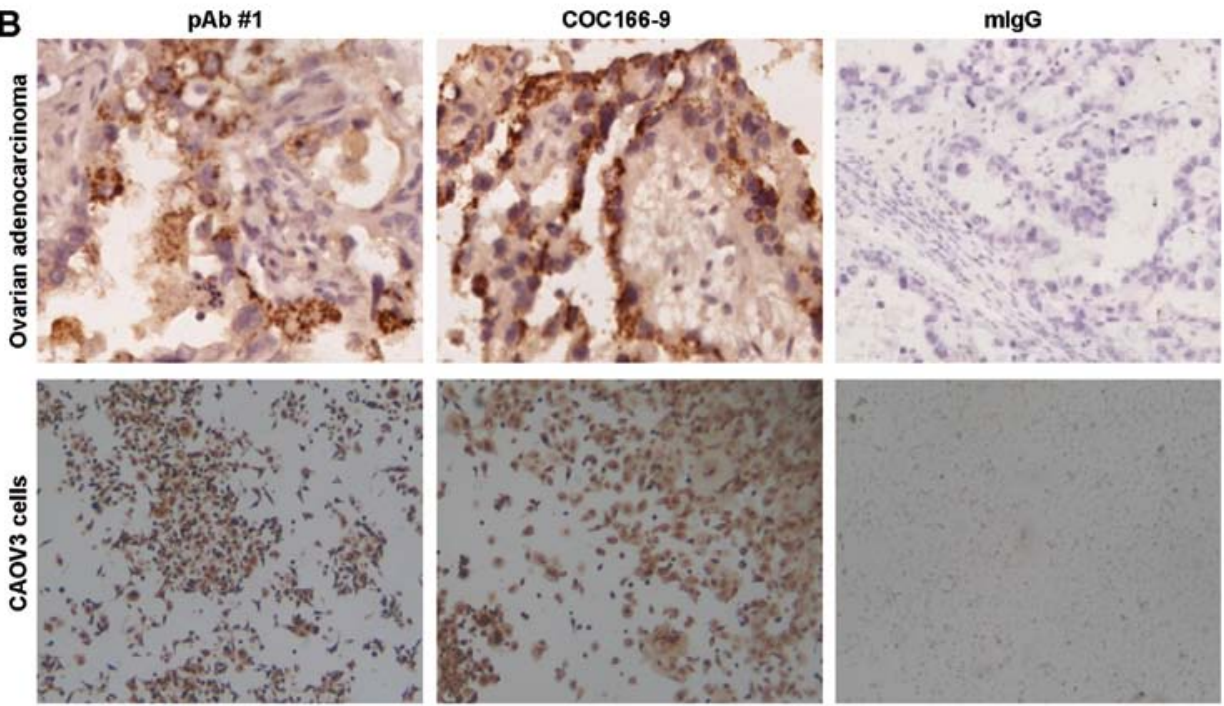

Figure 3. Generation of anti-CA166-9 polyclonal antibody. (A) ELISA analysis of anti-CA166-9 sera from two mice. CA166-9 and mouse IgG were used as positive and negative control, respectively. (B) Characterization of polyclonal anti-CA166-9 serum by immunohistochemical analysis of ovarian cancer tissue (upper panel) and immunocytochemical analysis of CAOV3 cells (lower panel).

ovarian cancer ascites were coated in microtiter plates. The results showed that the two polyclonal antibodies, but not pre-immune mouse serum, could recognize ovarian cancer ascites (Fig. 3A). To compare the immunoreactivity of prepared polyclonal antibody against CA166-9 with CA166-9, immunocytochemistry and immunohistochemistry analysis were performed. In all the five cases of ovarian cancer tissues, similar expression patterns were detected by the polyclonal anti-CA166-9 and monoclonal antibody COC166-9 (Fig. 3B). Immunocytochemical analysis of CA166-9 positive CAOV3 cells also obtained similar expression pattern with these two antibodies, with light or dark brown staining in the cytoplasm and the nuclei (Fig. 3B). These results further validated CA166-9 as IGHG1.

CA166-9 promotes ovarian cancer cell proliferation, migration and invasion in vitro. To explore the biological function of CA166-9, proliferation assay was conducted in the presence of purified IGHG1. The results showed that purified IGHG1 significantly promoted proliferation of CA166-9-negative HOC1A cells $(\mathrm{P}<0.05)$, whereas it had minimal effects on the proliferation of CA166-9 positive CAOV3 cells (Fig. 4A). By performing transwell chamber assays, we observed that
IGHG1 elevated migration (Fig. 4B, upper panel) and invasion (Fig. 4C, upper panel) of HOC1A cells, but those of CAOV-3 were not affected by IGHG1 (Fig. 4B and C, lower panel). To better substantiate the above results, IGHG1 was cloned and ectopically expressed in $3 \mathrm{AO}$ and SKOV3 cells (Fig. 4D). We found that exogenous IGHG1 markedly enhanced migration of these cells in the migration assay (Fig. 4E). To examine the effects of IGHG1 on non-cancerous cells, we treated human microvascular endothelial cells (HMEC) with IGHG1, but no obvious changes in the proliferation, migration, or invasion were found (data not shown).

Antibody COC166-9 decreases ovarian cancer cell proliferation, migration and invasion in vitro. Since IGHG1 promoted proliferation, migration and invasion of a subset of ovarian cancer cells, it is likely that IGHG1 has oncogenic functions in the tumor development. We thus explored whether COC166-9 has any therapeutical effects. It was shown that COC166-9 decreased the proliferation, migration, and invasion of CAOV3 cells (Fig. 5A-C, lower panels), but had no effect on those of HOC1A cells (Fig. 5A-C, upper panels) and HMEC (data not shown). These results also suggest that the impact of COC166-9 on ovarian cancer cell is CA166-9-specific. 
A
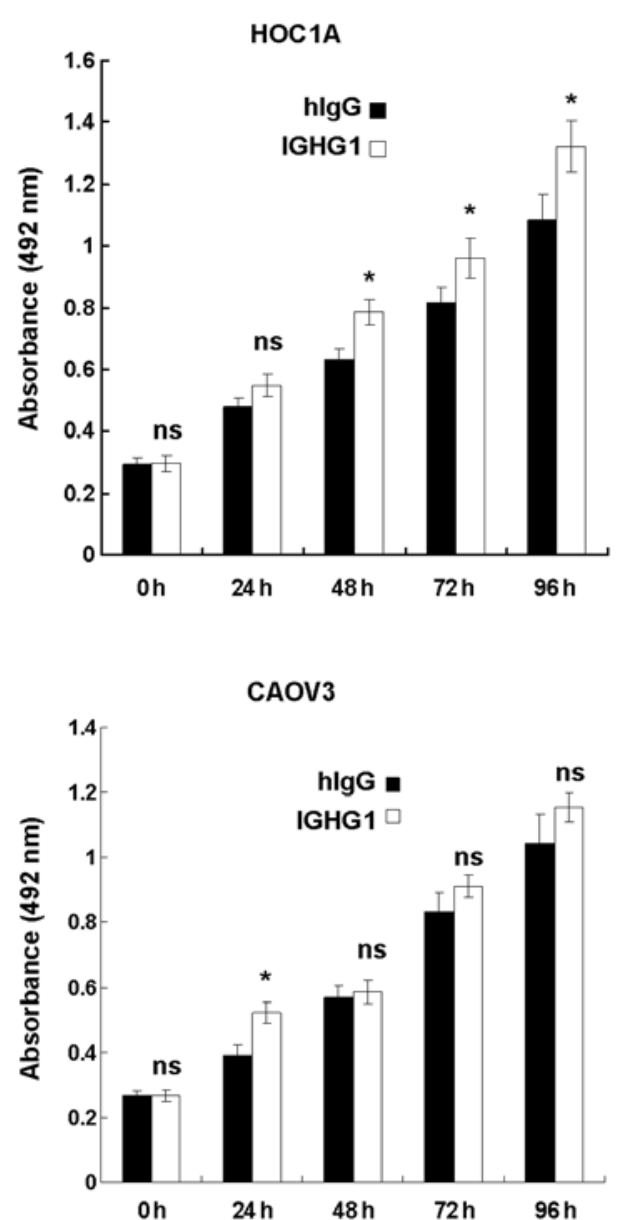

D
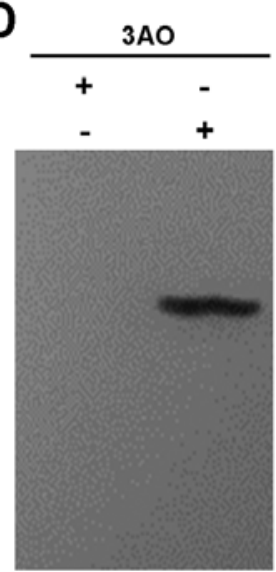

B
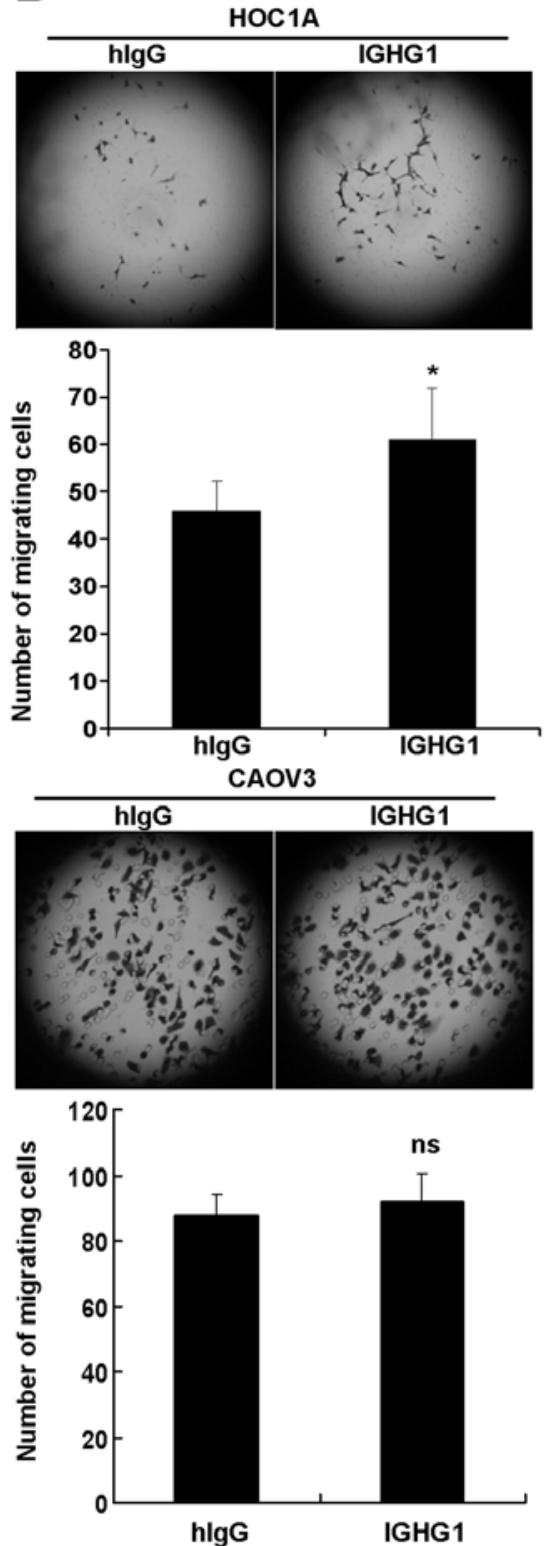

hlgG
C
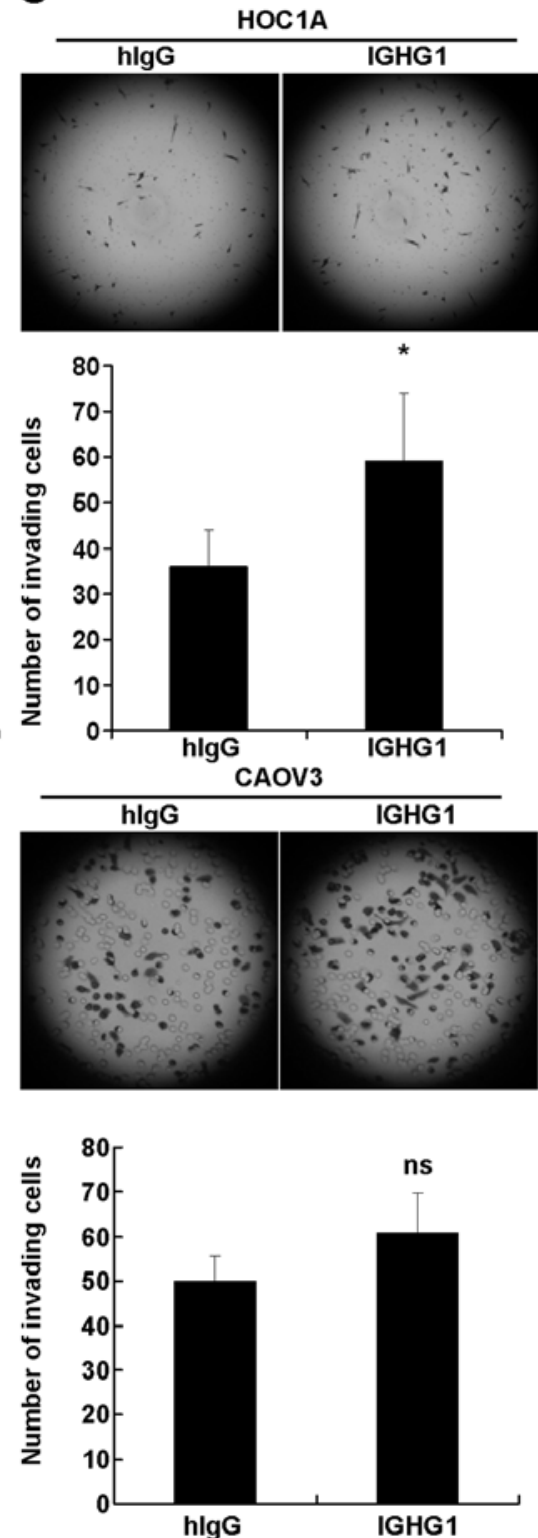

E

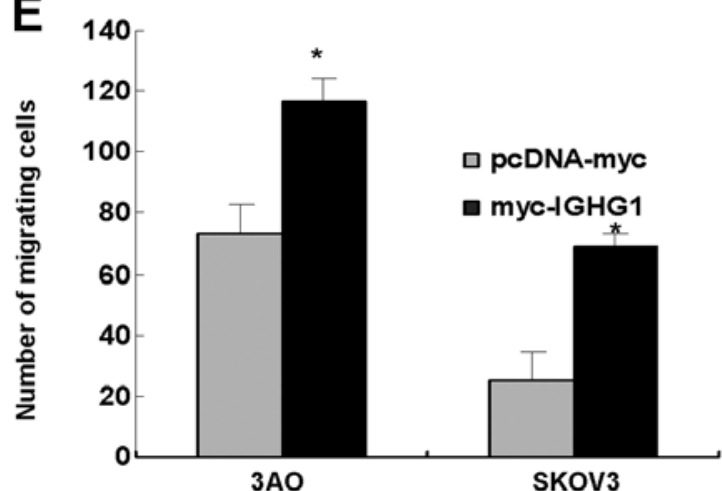

Figure 4. Effects of IGHG1 on the proliferation, migration, and invasion of ovarian cancer cells. (A) Effect of purified IGHG1 protein on cell proliferation. Cells were treated with $20 \mu \mathrm{g}$ IGHG1 or normal human IgG (control), proliferation was examined at indicated time-point by MTT assay. (B) Effect of purified IGHG1 protein on cell migration. Indicated cells were subjected to migration assay in the presence of $20 \mu \mathrm{g}$ IGHG1 or normal human IgG (control). Mean values of four view-fields were compared (bottom panel). Representative images are shown (upper panel). (C) Effect of purified IGHG1 protein on cell invasion. Indicated cells were subjected to invasion assay in the presence of $10 \mu \mathrm{g}$ IGHG1 or normal human IgG (control). Mean values of four view-fields were compared (bottom panel). Representative images are shown (upper panel). (D) Ectopic expression of myc-tagged IGHG1 in 3AO and SKOV3 cells, as checked by western blotting with anti-myc antibody. (E) Effect of ectopic IGHG1 on cells migration. Indicated cells were transfected with myc-tagged IGHG1. Twenty-four hours after transfection, cells were seeded in the transwell chamber and were allowed to migrate for $24 \mathrm{~h}$. Mean values of four view-fields were compared. ${ }^{*} \mathrm{P}<0.05$; NS, not significant. 
A

HOC1A

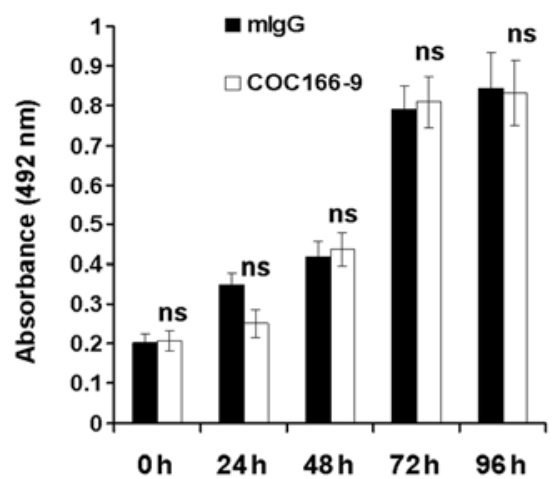

CAOV3

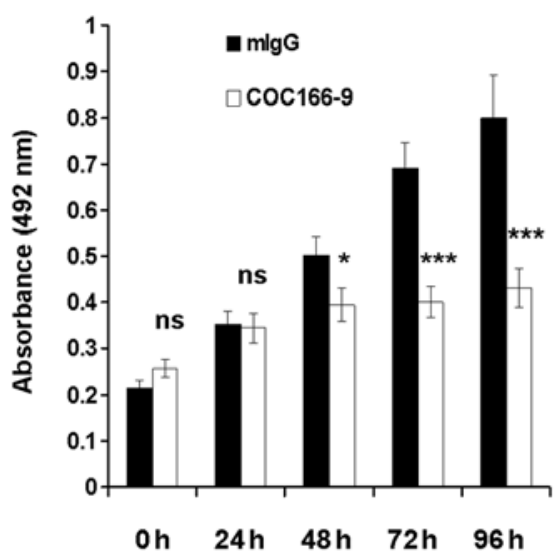

B
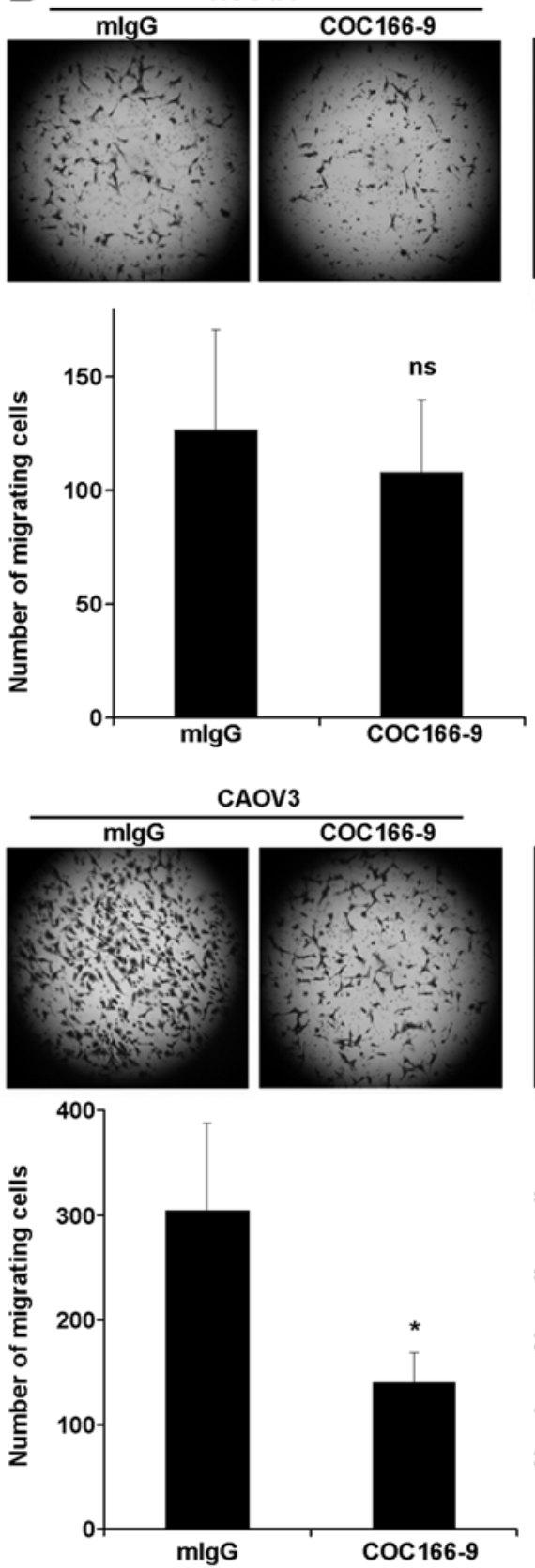

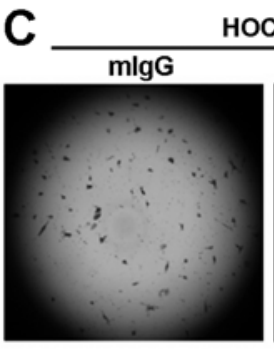

HOC1A
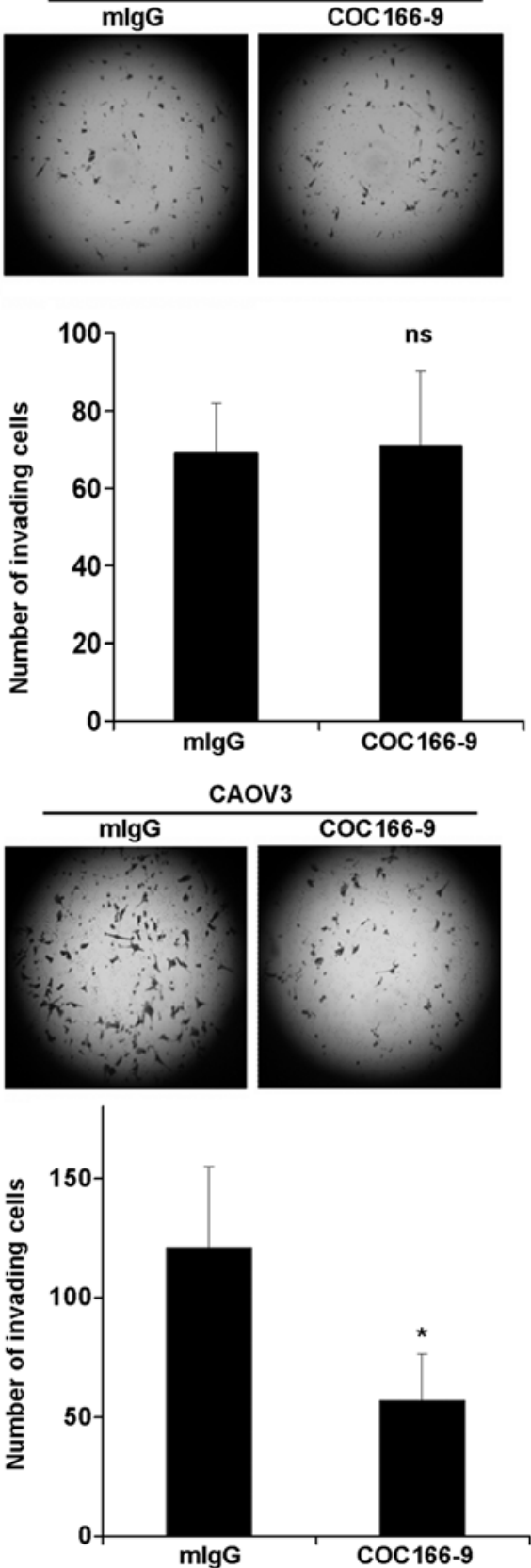

Figure 5. Effects of COC166-9 on the proliferation, migration, and invasion of ovarian cancer cells. (A) Effect of COC166-9 on cell proliferation. Cells were treated with $10 \mu \mathrm{g}$ COC166-9 or normal mouse IgG (control), proliferation was examined at indicated time-point by MTT assay. (B) Effect of purified COC166-9 on cell migration. Indicated cells were subjected to migration assay in the presence of $10 \mu \mathrm{g}$ COC166-9 or normal mouse IgG (control). Mean values of four view-fields were compared (bottom panel). Representative images are shown (upper panel). (C) Effect of purified COC166-9 on cell invasion. Indicated cells were subjected to invasion assay in the presence of $10 \mu \mathrm{g}$ COC166-9 or normal mouse IgG (control). Mean values of four view fields were compared (bottom panel). Representative images are shown (upper panel). ${ }^{*} \mathrm{P}<0.05 ;{ }^{* * *} \mathrm{P}<0.001 ; \mathrm{NS}$, not significant.

\section{Discussion}

COC166-9, a monoclonal antibody raised against human epithelial ovarian adenocarcinoma, was potential for immunodiagnosis and immunotherapy (7). However, the general application of this antibody had been precluded in the last two decades because its antigen, CA166-9, remained to be identified. In this study, firstly we evaluated prognostic value of CA166-9 expression in ovarian cancer. Our study revealed CA166-9 as an independent prognostic marker for patients with ovarian cancer. Although CA166-9 status had no correlation with some clinicopathologic characteristics, we did find that CA166-9 was closely associated with relapse. This could be explained by the results of functional analysis showing CA166-9's stimulatory effect on the proliferation, migration, and invasion of a subset of ovarian cancer cells. Therefore, CA166-9 may play some oncogenic roles in the progression of ovarian cancer cells. Importantly, antibody COC166-9 has a capacity of decreasing the proliferation, migration, and invasion of ovarian cancer cells in a CA166-9-dependent 
manner, further highlighting the therapeutic potential of this antibody.

Our results identified CA166-9 as IGHG1 constant region. Experiments including immunohistochemistry inhibition analysis and immunoprecipitation with streptococcal protein $\mathrm{G}$ proved that the CA166-9 was IgG-like protein. It is the first time that IGHG1 constant region, part of immunoglobulin, is demonstrated to be the tumor antigen of a monoclonal antibody. However, since the mass spectra we obtained after trypsin digestion did not show any information of the immunoglobulin heavy chain variable region, we could not determine the intact human immunoglobulin heavy chain sequence. Moreover, as the epitope recognized by COC166-9 appears to be confined within the constant region of IGHG1, it is deducible that different kinds of immunoglobulin heavy chains sharing the same IGHG1 constant region could be recognized by COC166-9, which explains why the antigen purified from ovarian cancer ascites migrated as five distinct bands.

Traditionally, it was believed that the only source of immunoglobulins (Igs) is mature B lymphocytes and plasma cells. However, some groups reported that Ig could also be detected in non-lymphoid cells, including epithelial cancer cells and proliferating epithelial cells. In 1998, Kimoto detected gene transcripts of the Ig heavy chain constant regions of $\operatorname{IgG} 1$, IgG3, IgA, IgD, IgE and IgM in five carcinoma cell lines by using nested RT-PCR (17). By employing cDNA microarray, a human immunoglobulin heavy chain constant region was found in hepatocellular carcinoma total RNA (18). Ig heavy chain protein could also be detected by two-dimensional electrophoresis in human nasopharyngeal carcinoma cell line (19). In 2003, IgG expression was reported in ovarian cancer $\mathrm{CaOV} 3$ cells by FACS analysis (20). In the same study, mRNA of IgG heavy chain was also identified in breast, colon, liver, and lung cancer cells and corresponding human cancers of epithelial origin (20). Immunohistochemistry analysis showed this IgG was localized in the cytoplasm or on the plasma membrane of these cells (20), in accordance with COC166-9 staining pattern in ovarian cancer cells and tissues observed in this study. In 2006, immunoglobulin heavy chain ( $\mathrm{IgH})$ gene transcripts was detected by nested RT-PCR in four well-defined breast cancer cell lines (21). Additionally, IgG protein expression was found in breast cancer, colorectal cancer, prostate cancer, and soft tissue tumors (22-25).

Regardless of the reports of Ig expression in epithelial cancer cells, the literature on its biological function remains limited. By using either antisense oligodeoxynucleotide or anti-human IgG antibody, it was found that blockade of tumorderived $\mathrm{IgG}$ significantly increased programmed cell death and inhibited cancer cells growth in vitro (20). In addition, IgG produced by cancer cells had some unidentified capacity to promote the growth and survival of tumor cells (20). Treatment of human colorectal cancer cell line LoVo with anti-human IgG resulted in decreased proliferation (23). Similarly, small interfering RNA-mediated silencing of cancerous Ig inhibited cell proliferation in vitro and suppressed xenograft growth in nude mice (26). These results support the concept that cancerderived Ig may function as a growth factor for cancer cells, in line with our study using purified CA166-9. Although the exact mechanism of Igs-induced tumor growth is unclear, it has been hypothesized that Igs may block target epitopes on the cancer cells (27). Hellstrom et al suggested that the ability of lymphocytes to eliminate their targets may be compromised in vivo by serum factors that protect the neoplastic cells specifically (akin to enhancing antibodies) or non-specifically (28). However, these hypotheses could not explain the inhibitory effect of cancer cell-derived Igs observed in the in vitro studies, thus it will be interesting to find the receptors of Igs on cancer cells and delineate the signaling events downstream of the engagement of Igs with cancer cells.

\section{Acknowledgements}

This study was supported by the Capital Medical Developing Foundation (2007-2052), the National Natural Science Foundation of China (30872750).

\section{References}

1. Jemal A, Siegel R, Xu J and Ward E: Cancer statistics, 2010. CA Cancer J Clin 60: 277-300, 2010.

2. Memarzadeh S, Lee SB, Berek JS and Farias-Eisner R: CA125 levels are a weak predictor of optimal cytoreductive surgery in patients with advanced epithelial ovarian cancer. Int J Gynecol Cancer 13: 120-124, 2003.

3. Bast RC Jr, Xu FJ, Yu YH, Barnhill S, Zhang Z and Mills GB: CA 125: The past and the future. Int J Biol Markers 13: 179-187, 1998.

4. Bast RC Jr, Skates S, Lokshin A and Moore RG: Differential diagnosis of a pelvic mass: Improved algorithms and novel biomarkers. Int J Gynecol Cancer 22 (Suppl 1): S5-S8, 2012.

5. Salani R, Backes FJ, Fung MF, Holschneider CH, Parker LP, Bristow RE and Goff BA: Posttreatment surveillance and diagnosis of recurrence in women with gynecologic malignancies: Society of Gynecologic Oncologists recommendations. Am J Obstet Gynecol 204: 466-478, 2011.

6. Qian HN, Feng J, Cui H, Fu TY, Wei P and Fu ZY: Generation and characterization of three monoclonal antibodies to human ovarian epithelial adenocarcinomas. Chin Med J (Engl) 102: 839-843, 1989.

7. Qian HN: Immunohistological analysis of monoclonal antibody COC166-9 against primary ovarian epithelial cancer. Zhonghua Bing Li Xue Za Zhi 17: 207-209, 1988 (In Chinese).

8. Qian HN and Li WJ: Target therapy of ovarian carcinoma by monoclonal antibodies bearing chemical drugs entrapped in liposomes. Chin Med J (Engl) 106: 343-347, 1993.

9. Li X, Qian H and Feng J: Preparation of F(ab')2 fragment of monoclonal antibody COC166-9 and its experimental study of radioimmunoimaging for ovarian carcinoma. Zhonghua $\mathrm{Fu} C \mathrm{Chan}$ Ke Za Zhi 32: 152-155, 1997 (In Chinese).

10. Chang X, Cui H, Feng J, Li Y, Liu B, Cao S, Cheng Y and Qian H: Preparation of humanized ovarian carcinoma anti-idiotypic minibody. Hybrid Hybridomics 22: 109-115, 2003.

11. Feng J, Lü J and Qian H: Serological analysis of antibodies by anti-idiotypic monoclonal antibody 6B11 against ovarian carcinoma. Zhonghua Fu Chan Ke Za Zhi 31: 493-495, 1996 (In Chinese).

12. Cui H, Chang XH, Liu B, Feng J, Li Y, Ye X, Cao SJ, Fu TY, Yao Y, Li HQ, et al: The anti-tumor immune responses induced by a fusion protein of ovarian carcinoma anti-idiotypic antibody $6 \mathrm{~B} 11 \mathrm{ScF}$ and murine GM-CSF in BALB/c mice. Int $\mathrm{J}$ Gynecol Cancer 14: 234-241, 2004.

13. Shi J, Chang X, Feng J, Cheng Y, Cheng H, Guo H, Ye X and Cui H: Expression of an ovarian cancer anti-idiotype antibody (6B11VLVHCH3) in Chinese hamster ovary (CHO) cells with improved immunoactivity and stability over proteins expressed in prokaryotic cells. Hybridoma (Larchmt) 26: 289-295, 2007.

14. Yang W, Feng J, Chang X, Fu T, Ye X, Zhang H, Li X, Wen H, Feng L, Tong C, et al: Cytotoxic effects of T cells induced by fusion protein 6B11-pulsed dendritic cells on ovarian carcinoma cells. Gynecol Oncol 105: 238-243, 2007.

15. Li W, Cui H, Meng FQ, Chang XH, Zhang G, Liu B and Li ZH: New $T$ cell epitopes identified from an anti-idiotypic antibody mimicking ovarian cancer associated antigen. Cancer Immunol Immunother 57: 143-154, 2008. 
16. Stone GC, Sjöbring U, Björck L, Sjöquist J, Barber CV and Nardella FA: The Fc binding site for streptococcal protein $G$ is in the $\mathrm{C}$ gamma 2-C gamma 3 interface region of $\mathrm{IgG}$ and is related to the sites that bind staphylococcal protein A and human rheumatoid factors. J Immunol 143: 565-570, 1989.

17. Kimoto Y: Expression of heavy-chain constant region of immunoglobulin and T-cell receptor gene transcripts in human non-hematopoietic tumor cell lines. Genes Chromosomes Cancer 22: 83-86, 1998 .

18. Okabe H, Satoh S, Kato T, Kitahara O, Yanagawa R, Yamaoka Y, Tsunoda T, Furukawa Y and Nakamura Y: Genome-wide analysis of gene expression in human hepatocellular carcinomas using cDNA microarray: Identification of genes involved in vira carcinogenesis and tumor progression. Cancer Res 61: 2129-2137, 2001.

19. Li J, Tan C, Xiang Q, Zhang X, Ma J, Wang JR, Yang J, Li W, Shen SR, Liang S, et al: Proteomic detection of changes in protein synthesis induced by NGX6 transfected in human nasopharyngeal carcinoma cells. J Protein Chem 20: 265-271, 2001 .

20. Qiu X, Zhu X, Zhang L, Mao Y, Zhang J, Hao P, Li G, Lv P, Li Z, Sun X, et al: Human epithelial cancers secrete immunoglobulin $\mathrm{G}$ with unidentified specificity to promote growth and survival of tumor cells. Cancer Res 63: 6488-6495, 2003

21. Babbage G, Ottensmeier CH, Blaydes J, Stevenson FK and Sahota SS: Immunoglobulin heavy chain locus events and expression of activation-induced cytidine deaminase in epithelial breast cancer cell lines. Cancer Res 66: 3996-4000, 2006.
22. Ma C, Wang Y, Zhang G, Chen Z, Qiu Y, Li J, Luo J, Huang B, Jiang $C$, Huang $G$, et al: Immunoglobulin $G$ expression and its potential role in primary and metastatic breast cancers. Curr Mol Med 13: 429-437, 2013.

23. Niu N, Zhang J, Huang T, Sun Y, Chen Z, Yi W, Korteweg C, Wang $\mathrm{J}$ and $\mathrm{Gu} \mathrm{J}$ : IgG expression in human colorectal cancer and its relationship to cancer cell behaviors. PLoS One 7: e47362, 2012.

24. Liu Y, Chen Z, Niu N, Chang Q, Deng R, Korteweg C and Gu J: $\mathrm{IgG}$ gene expression and its possible significance in prostate cancers. Prostate 72: 690-701, 2012.

25. Chen Z, Huang X, Ye J, Pan P, Cao Q, Yang B, Li Z, Su M, Huang $\mathrm{C}$ and $\mathrm{Gu} \mathrm{J}$ : Immunoglobulin $\mathrm{G}$ is present in a wide variety of soft tissue tumors and correlates well with proliferation markers and tumor grades. Cancer 116: 1953-1963, 2010.

26. Li M, Zheng H, Duan Z, Liu H, Hu D, Bode A, Dong Z and Cao Y: Promotion of cell proliferation and inhibition of ADCC by cancerous immunoglobulin expressed in cancer cell lines. Cell Mol Immunol 9: 54-61, 2012.

27. Manson LA: Anti-tumor immune responses of the tumor-bearing host: The case for antibody-mediated immunologic enhancement. Clin Immunol Immunopathol 72: 1-8, 1994.

28. Hellström I, Hellström KE, Evans CA, Heppner GH, Pierce GE and Yang JP: Serum-mediated protection of neoplastic cells from inhibition by lymphocytes immune to their tumor-specific antigens. Proc Natl Acad Sci USA 62: 362-368, 1969. 